\title{
Airway obstruction in a child with asymptomatic tracheobronchomalacia
}

\author{
[Obstruction des voies aériennes chez un enfant atteint de trachéo-bronchomalacie \\ asymptomatique]
}

Takashi Asai MD PhD, Koh Shingu MD

Purpose: To report a case of airway obstruction with hypoxia during emergence from anesthesia due to unexpected tracheobronchomalacia in a child.

Clinical features: In a previously healthy 22-month-old boy with no symptoms or signs of respiratory disease, general anesthesia was induced by inhalation of increasing concentrations of sevoflurane (up to 5\%) in oxygen and a laryngeal mask was inserted. Partial airway obstruction persisted during surgery, but obstruction was relieved by positive-pressure ventilation. During emergence from anesthesia, airway obstruction with hypoxia occurred, necessitating tracheal intubation. Emission of carbon dioxide as well as of sevoflurane was reduced and emergence from anesthesia markedly delayed. Fibreoptic tracheoscopy showed marked collapse of the tracheobronchi during expiration, and a diagnosis of tracheobronchomalacia was made. No respiratory complications occurred postoperatively.

Conclusion: Asymptomatic tracheomalacia should also be suspected in case of airway obstruction during anesthesia in young chitdren.

Objectif : Présenter un cas d'obstruction des voies aériennes avec hypoxie, survenue pendant le retour à la conscience et causée par une trachéo-bronchomalacie inattendue chez un enfant.

Éléments cliniques : Chez un enfant de 22 mois, auparavant en bonne santé, qui ne présentait aucun signe ou symptôme d'affection respiratoire, on a induit l'anesthésie générale par l'inhalation de concentrations croissantes de sévoflurane (jusqu'à 5 \%) dans de l'oxygène et mis en place un masque laryngé. L'obstruction partielle des voies aériennes a persisté pendant l'intervention chirurgicale, mais a été soulagée par la ventilation à pression positive. Pendant le retour à la conscience, l'obstruction des voies aériennes accompagnée d'hypoxie ont nécessité une intubation endotrachéale. L'expiration de gaz carbonique, et du sévoflurane, a été réduite et le réveil retardé de façon marquée. La fibroscopie trachéoscopique a montré un important affaissement trachéo-bronchique pendant l'expiration, suggérant une trachéo-bronchomalacie. II n'y a eu aucune complication respiratoire postopératoire.

Conclusion : La trachéo-malacie asymptomatique devrait être envisagée en cas d'obstruction des voies aériennes pendant l'anesthésie de jeunes enfants.

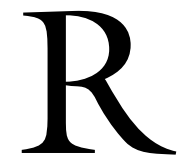

ESPIRATORY complications may occur more frequently during emergence from anesthesia than during its induction, and one major complication during emergence from anesthesia is hypoxia due to airway obstruction. ${ }^{1}$ We report a case of airway obstruction with hypoxia during emergence from anesthesia due to unexpected tracheobronchomalacia in a child. Symptomatic tracheobronchomalacia is known to cause airway obstruction during general anesthesia, ${ }^{2}$ but we were unable to find any previous report of severe hypoxia in a patient with asymptomatic tracheomalacia.

\section{Clinical features}

A 22 -month-old boy, $80 \mathrm{~cm}, 10 \mathrm{~kg}$, with an erythematous lesion on the right arm was scheduled for resection of the cutaneous lesion under anesthesia on an outpatient basis. He was born as a full-term baby and had been a previously healthy child. He had no symptoms or signs of respiratory disease necessitating tracheal intubation, and his parents did not notice any marked difficulties with breathing during respiratory infections. Preoperatively, lung sounds were clear on auscultation. Routine laboratory examinations, including electrocar-

From the Department of Anesthesiology, Kansai Medical University, Osaka, Japan.

Address correspondence to: Dr. Takashi Asai, Department of Anesthesiology, Kansai Medical University, 10-15 Fumizono-cho,

Moriguchi City, Osaka, 570-8507, Japan. Phone: 0081-6-6992-1001; Fax: 0081-6-6991-1301; E-mail: asait@takii.kmu.ac.jp Accepted for publication February 15, 2001.

Revision accepted April 2,2001. 
diogram, chest $x$-ray and blood chemistry, were within normal limits. No premedicants were given.

In the operating room, an electrocardiograph, a pulse oximeter and a blood pressure cuff were attached. Anesthesia was induced by inhalation of increasing concentrations of sevoflurane (up to 5\%) in oxygen while the patient was breathing spontaneously. An iv cannula was inserted on the dorsum of the hand. Approximately five minutes after the patient had lost consciousness, spontaneous breathing became irregular and the airway was partially obstructed, mainly during expiration. Thrusting the jaw forward reduced, but did not abolish, the obstruction. Suctioning of the oropharyngeal cavity aspirated a little saliva and did not relieve the obstruction.

A size 2.5 laryngeal mask was inserted easily, but partial airway obstruction persisted. Manual ventilation through the laryngeal mask relieved the airway obstruction. When ventilation was not assisted, wheezing was heard at auscultation of the chest, but less at the neck, indicating that the airway was likely to be obstructed in the chest rather than in the oropharynx or in the larynx. Since partial airway obstruction had occurred before insertion of the laryngeal mask, auscultation indicated obstruction in the chest, and ventilation was relieved by manual ventilation, we felt that it was not necessary to remove the laryngeal mask. Deep anesthesia was maintained (3-5\% sevoflurane and $50 \%$ nitrous oxide in oxygen) to avoid airway reflexes. Analgesics consisted of flurbiprofen (a nonsteroidal anti-inflammatory drug) $10 \mathrm{mg}$ injected intravenously and local infiltration of lidocaine. Neither opioids nor neuromuscular blocking agents were given. During operation (which lasted $65 \mathrm{~min}$ ), the airway remained partially obstructed when ventilation was not assisted. Arterial hemoglobin oxygen saturation $\left(\mathrm{SpO}_{2}\right)$ remained greater than $98 \%$ (with an inspired oxygen concentration of $50 \%$ ).

At the end of surgery while still under deep anesthesia, the patient was turned to the left lateral decubitus position, the laryngeal mask was removed, and sevoflurane discontinued. Partial airway obstruction persisted even after removal of the mask, but no oropharyngeal airway was inserted in fear of causing laryngospasm. About five minutes later, the airway obstructed further. Expiration became markedly prolonged. Manual ventilation with the jaw-thrust manoeuver was attempted, but it was difficult to inflate the lungs. The $\mathrm{SpO}_{2}$ decreased to $88 \%$. The patient was turned to the supine position and the trachea was intubated without further delay (without the use of neuromuscular blocking agent). At laryngoscopy, the glottis was open, indicating that laryngospasm was unlikely. The $\mathrm{SpO}_{2}$ was $65 \%$ at this point. Manual ventilation with $5 \%$ sevoflurane in oxygen through the tracheal tube was attempted, but it was still difficult to inflate the lungs and $\mathrm{SpO}_{2}$ further decreased to $46 \%$. However, within one minute, it became possible to inflate the lungs and $\mathrm{SpO}_{2}$ rapidly increased to $98 \%$. When ventilation was not manually assisted, marked intercostal and substernal retractions reappeared during inspiration; expiration remained markedly prolonged. Chest percussion did not relieve the obstruction, and little sputum was collected by suctioning to the airway. Bronchospasm was considered to be unlikely, since there was little difficulty in ventilating the lungs manually.

During the next hour, respiratory rate was 25-30 breaths. $\mathrm{min}^{-1}, \mathrm{PETCO}_{2}$ was $65-70 \mathrm{mmHg}$ when ventilation was not assisted, and the $\mathrm{SpO}_{2}$ decreased below $94 \%$ when the patient breathed room air. Despite assisted ventilation, there was a marked delay in the decrease in end-tidal sevoflurane concentration, and the patient had not regained consciousness 55 min after cessation of sevoflurane. Expiratory airway obstruction and the increased $\mathrm{PETCO}_{2}$ (and delayed emergence from sevoflurane) led us to suspect that the patient might have tracheomalacia. Emergency fibreoptic bronchoscopy revealed that the lower trachea and bilateral main bronchi narrowed markedly during expiration.

Over the next $30 \mathrm{~min}$ (a total of $90 \mathrm{~min}$ after cessation of sevoflurane), $\mathrm{PETCO}_{2}$ had decreased to 52 mmHg but hypoxia occurred when oxygen administration was stopped. The patient became agitated with laboured breathing and substernal retraction, and manual ventilation with $5 \%$ sevoflurane was resumed. After breathing had become easier, the sevoflurane concentration was decreased gradually to $0.5 \%$ over the next hour. A chest $x$-ray taken during this period showed normal lung fields. Prolongation of expiration became less pronounced, $\mathrm{PETCO}_{2}$ gradually decreased to $44 \mathrm{mmHg}$, and $\mathrm{SpO}_{2}$ remained at $98 \%$ while breathing room air. Sevoflurane was discontinued, and the patient regained consciousness within five minutes. The child breathed easily and expiration was not prolonged. The trachea was extubated five minutes later. No airway obstruction occurred and $\mathrm{SpO}_{2}$ remained $98 \%$ afterwards. A diagnosis of congenital tracheobronchomalacia, extending from the lower trachea to the bronchi bilaterally, was made. Postoperatively, the patient's parents again denied any sign of airway obstruction during daily life. Interview at one month after surgery showed that the patient had remained asymptomatic after surgery.

\section{Discussion}

We report the case of a child with unexpected tracheobronchomalacia in whom airway obstruction with 
severe hypoxia occurred during anesthesia. Despite the absence of any apparent airway obstruction preoperatively, airway obstruction during anesthesia was so severe it required tracheal intubation. Elimination of carbon dioxide and sevoflurane was reduced and emergence from anesthesia markedly delayed.

In our patient, the airway became obstructed after induction of general anesthesia, while the patient was breathing spontaneously, but obstruction was relieved by manual ventilation. In a previous report of a 68 -yrold obese woman, in whom anesthesia was induced and the trachea intubated uneventfully, laboured breathing secondary to unexpected tracheomalacia appeared during expiration, when the effect of succinylcholine had worn off and spontaneous breathing had resumed. ${ }^{3}$ Difficulties during spontaneous breathing and a relief of symptoms by manual ventilation have been reported in patients with known tracheomalacia or tracheal stenosis. ${ }^{2,4}$ However, if obstruction is severe, it may not be relieved by positive pressure, ${ }^{2,4}$ as in this case.

The exact mechanism of airway obstruction during spontaneous breathing under general anesthesia and its relief by intermittent positive pressure ventilation remains unknown. A likely mechanism is that, during normal breathing, intrapleural pressure is always slightly more negative than the intratracheal pressure and, thus, the airway remains open. ${ }^{5,6}$ However, during forced expiration (such as coughing or in the patient who needs to overcome the increased airway resistance at the level of the lower trachea (e.g., tracheobronchomalacia)) both intrapleural pressure and alveolar pressure markedly increase. Because the pressure decreases along the airway in direction of the thoracic outlet, the trachea will be subjected to a compressing transmural pressure that increases towards the thoracic outlet. ${ }^{5,6}$ When positive pressure is applied to the airway during forced expiration, the gradient between the intrathoracic and intratracheal pressures is reduced; therefore, tracheal collapse is, in theory, less likely to occur during controlled ventilation than during spontaneous breathing. In fact, several authors have reported that continuous positive airway pressure, with or without intermittent positive pressure ventilation, alleviates tracheal collapse..$^{5-8}$

In our patient, airway obstruction occurred on several occasions and was due probably to multiple causes. Partial airway obstruction occurred during anesthesia, the obstruction worsened during emergence from anesthesia (after removal of the laryngeal mask), obstruction was not relieved temporarily after tracheal intubation and obstruction re-appeared when the patient agitated (in the presence of a tracheal tube). The decrease in muscle tone during anesthesia, marked changes of the intrapleural-intratracheal pressure relationship during emergence from anesthesia and bronchospasm were probably the major causes.

The treatment and prevention of symptoms associated with tracheomalacia during anesthesia has not been established, but a few can be suggested, based on our case. First, airway obstruction may occur during emergence from anesthesia, since airway dynamics (intrapleural-intratracheal pressures) may markedly change during this period. Second, it is important not to cause straining ('bucking'), since forced expiration worsens the narrowing of the lower airway. ${ }^{5}$ Third, if airway obstruction occurs, deepening of anesthesia may reduce the obstruction, since the intrathoracic pressure during expiration is lower under general anesthesia than during the awake state ${ }^{9}$ and it has been claimed that tracheal collapse is less severe during general anesthesia. ${ }^{10}$ Continuous or intermittent positive pressure ventilation may also relieve the obstruction. Nevertheless, if hypoxia occurs, the trachea should immediately be intubated, and the lungs ventilated manually.

The use of a neuromuscular blocking agent may have a role in relieving airway collapse and preventing airway reflexes. ${ }^{3}{ }^{4}$ However, caution is required when using these drugs since they may worsen obstruction if the cause of obstruction is not, in fact, tracheomalacia but a mechanical obstruction such as a mediastinal mass or foreign body.

Generally, the best timing of tracheal extubation is either when the patient is still deeply anesthetized or when he has regained consciousness ${ }^{1,11}$ but both methods may cause difficulties in the patient with tracheobronchomalacia. Tracheal extubation after the patient has regained consciousness (and after the intrapleural-intratracheal pressure relationship has become 'normal') will reduce the incidence of airway collapse, but straining in response to the presence of a tracheal tube may induce bronchospasm and obstruction. In our case, the patient became agitated with laboured breathing and substernal retraction, and thus it became necessary to deepen anesthesia. On the other hand, tracheal extubation while the patient is still deeply anesthetized is less likely to cause straining and bronchospasm, but expiratory airway obstruction during emergence from anesthesia can occur, as in our case, after removal of the laryngeal mask. It appears that the trachea should be left intubated until the patient has regained consciousness and the intrapleural-intratracheal pressure relationship has become 'normal' and no attempts be made to wake the patient to avoid causing strain. After tracheal extubation, positive pressure ventilation via a facemask can be used to prevent airway obstruction. ${ }^{12}$ 
Differential diagnosis of tracheobronchomalacia includes laryngospasm, bronchospasm, laryngomalacia, vocal cord palsy, tracheal stenosis, laryngeal or tracheal web, intratracheal tumour, external compression to the airway (e.g., vascular ring, mediastinal mass), and bronchial intubation. ${ }^{13-15}$ Auscultation, chest $x$ rays and endoscopy are useful to reach a diagnosis.

Our case indicates that marked airway obstruction can occur in a patient with tracheomalacia, even if there have been no respiratory symptoms during daily life. The incidence of asymptomatic tracheomalacia remains unknown, but respiratory symptoms may not be manifest for some time. After studying 21 children with tracheomalacia, Blair and colleagues reported that respiratory symptoms did not appear until the age of two to three months in 20 patients (95\%), and that the diagnosis of tracheomalacia had not been made for as long as 96 months of age. ${ }^{16}$ We conclude that asymptomatic tracheomalacia should also be suspected if airway obstruction occurs during anesthesia in an infant.

\section{References}

1 Asai T, Koga K, Vaughan RS. Respiratory complications associated with tracheal intubation and extubation. Br J Anaesth 1998; 80: 767-75.

2 Okuda $\Upsilon$, Sato H, Kitajima T, Asai T. Airway obstruction during general anaesthesia in a child with congenital tracheomalacia. Eur J Anaesthesiol 2000; 17: 642-4.

3 Katoh H, Saitoh S, Takiguchi M, Yamasaki $\Upsilon$, ramamoto $M$. A case of tracheomalacia during isoflurane anesthesia. Anesth Analg 1995; 80: 1051-3.

4 Asai T, Fujise K, Uchida M. Use of the laryngeal mask in a child with tracheal stenosis. Anesthesiology 1991; 75: 903-4.

5 Wiseman NE, Duncan PG, Cameron CB. Management of tracheomalacia with continuous positive airway pressure. J Pediatr Surg 1985; 20: 489-90.

6 Wittenborg $M H$, Gyepes MT, Crocker D. Tracheal dynamics in infants with respiratory distress, stridor, and collapsing trachea. Radiology 1967; 88: 653-62.

7 Collard PH, Freitag L, Reynaert MS, et al. Respiratory failure due to tracheobronchomalacia. Thorax 1996; 51: 224-6.

8 Kanter RK, Pollack MM, Wright WW, et al. Treatment of severe tracheobronchomalacia with continuous positive airway pressure (CPAP). Anesthesiology 1982; 57: 54-6.

9 Nuntine J. Acquired tracheobronchomalacia. Eur J Resp Dis 1982; 63: 380-7.

10 Baxter JD, Dunbar JS. Tracheomalacia. Ann Otol Rhinol Laryngol 1963; 72: 1013-23.

11 Koga K, Asai T, Vaughan RS, Latto IP. Respiratory complications associated with tracheal extubation.
Timing of tracheal extubation and use of the laryngeal mask during emergence from anaesthesia. Anaesthesia 1998; 53: 540-4.

12 Bouchut JC, Stamm D, Floret D Postoperative ventilatory management with noninvasive positive-pressure ventilation in a child with a severe tracheomalacia. Anesthesiology 2000; 93: 1562-3.

13 Gonzalez C, Reilly JS, Blustone CD. Synchronous airway lesions in infancy. Ann Otol Rhinol Laryngol 1987; 96: 77-80.

14 Holinger LD. Etiology of stridor in the neonate, infant and child. Ann Otol Rhinol Laryngol 1980; 89: 397-400.

15 Baxter MRN. Congenital laryngomalacia. Can J Anaesth 1994; 41: 332-9.

16 Blair GK, Cohen R, Filler RM. Treatment of tracheomalacia: eight years' experience. J Pediatr Surg 1986; 21: 781-5. 